\title{
Cannabis Use Disrupts Eyeblink Conditioning: Evidence for Cannabinoid Modulation of Cerebellar-Dependent Learning
}

\author{
Patrick D Skosnik*,', Chad R Edwards', Brian F O’Donnell', Ashley Steffen', Joseph E Steinmetz ${ }^{2}$ and \\ William P Hetrick'
}

'Department of Psychological and Brain Sciences, Indiana University, Bloomington, IN, USA; ${ }^{2}$ Department of Psychology, University of Kansas, Lawrence, KS, USA

\begin{abstract}
While the cerebellum contains the highest density of cannabinoid receptor (CBI) in the brain, no studies have assessed the effect of exogenous cannabinoids on cerebellar-dependent learning in humans. The current study, therefore, examined the effect of chronic cannabis use on classical eyeblink conditioning (EBC), a cerebellar-mediated task which has been shown to be disrupted in CBI knockout mice. Chronic cannabis users (24h abstinence before study; positive THC urine drug test) free of DSM-IV Axis-I or -II disorders, were evaluated. A delay EBC task was utilized, in which a conditioned stimulus (CS; 400 ms tone) co-terminated with a corneal air puff unconditioned stimulus (US; $50 \mathrm{~ms}$ ), thus eliciting a conditioned blink response (CR). The cannabis group exhibited markedly fewer, and more poorly timed CRs as compared to drug-naive controls. There were no differences between the groups in either the unconditioned response (UR) or an EEG measure of selective attention to the CS (NI00 auditory ERP), indicating that the disruption observed in the cannabis group was specific to $C R$ acquisition. These results suggest that cannabis use is associated with functional deficits in the cerebellar circuitry underlying EBC, a finding which corroborates the recent work in CBI knockout mice.

Neuropsychopharmacology (2008) 33, 1432-1440; doi:I 0. I038/sj.npp. I 30 I506; published online I 8 July 2007
\end{abstract}

Keywords: THC; cannabinoid; cerebellum; eyeblink conditioning; behavior; human

\section{INTRODUCTION}

Cannabis sativa remains one of the most widely used psychoactive substances in the world. In the United States alone, over 94 million individuals have used cannabis at least once in their lifetime (approximately $40 \%$ of the population; Substance Abuse Mental Health Services Administration, 2004). The principal psychoactive constituent in cannabis, $\Delta$-9-tetrahydrocannabinol (THC; Gaoni and Mechoulam, 1964), affects the brain via the action of central cannabinoid receptors (CB1; Devane et al, 1988). The subsequent discovery of several endogenous cannabinoid neuromodulators, namely anandamide and 2 -arachidonylglycerol (2-AG) has led to an exponential growth in cannabinoid research (Devane et al, 1992; Stella et al, 1997). However, despite substantial advances in the molecular and biochemical aspects of endocannabinoid function, little is known about the specific role that this system plays at behavioral level, particularly in the context of chronic cannabis use.

\footnotetext{
* Correspondence: Dr PD Skosnik, Department of Psychological and Brain Sciences, Indiana University, I I 0 I East IOth Street, Bloomington, IN 47405, USA, Tel: + I 812320 2521, Fax: + I 812855 469|,

E-mail: pskosnik@indiana.edu

Received 5 December 2006; revised 17 May 2007; accepted 8 June 2007
}

To date, the majority of studies assessing the effects of cannabis on human brain function have focused on higher sensory, attentional, and memory processes (Patrick et al, 1995, 1997; Iversen, 2003; Skosnik et al, 2001, 2006a, b; Ramaekers et al, 2006; Jager et al, 2007). However, several of these studies have led to ambiguous and equivocal results, which may be due to the fact that tasks evaluating higher cognitive processes probe the integrity of distributed neocortical networks (ie neocortical areas contain relatively moderate CB1 densities compared with structures such as the basal ganglia and the cerebellum). Tasks which examine cerebellar function should be particularly useful indices of the effects of exogenous cannabinoids, as the cerebellum contains the highest density of CB1 receptors in the brain (Herkenham et al, 1990; Pertwee, 1997; Tsou et al, 1998). In addition to its role in motor coordination, the cerebellum is thought to play a key role in temporal operations such as rhythm production, time estimation, and some forms of associative learning (Ivry and Keele, 1989; Katz and Steinmetz, 2002; Leiner et al, 1991). Indeed, altered time perception is one of the most frequently reported subjective experiences associated with acute cannabis intoxication (Hicks et al, 1984; Mathew et al, 1998), which is thought to be modulated by the cerebellum (O'Leary et al, 2003). Thus, studies examining cerebellar-mediated processes may provide important clues in relation to the subjective effects of cannabis and the role of the endocannabinoid system in normal brain function. 
Of the experiments which have evaluated cannabinoid effects on time estimation, several have shown that direct cannabis administration induces temporal disintegration, which is typically exhibited in the form of increased internal clock speeds (the experience of time passing more slowly; Hicks et al, 1984; Mathew et al, 1998; O'Leary et al, 2003). In relation to cerebellar modulation of cannabis' effect on time perception, a study integrating behavioral measures of temporal processing with neuroimaging methodologies has yielded positive results. Using PET, O'Leary et al (2003) demonstrated that cannabis-induced alterations in a selfpaced timing task were correlated with the increased activity of medial cerebellar cortex. Interestingly, cerebellar metabolism during acute cannabis administration has been shown to correlate with subjective ratings of intoxication (Volkow et al, 1996). While it is clear that cannabis use in humans affects cerebellar function, time estimation tasks such as those described above probably recruit a distributed neural network including such structures as basal ganglia and neocortex (Bengtsson et al, 2005), making specific interpretations regarding cannabinoid effects on cerebellar function difficult. What is needed is a probe specific to cerebellar function that is based upon well-established neural circuitry, while solely dependent on the cerebellum.

One such task which has been shown to be modulated almost completely by the cerebellum is classical eyeblink conditioning (EBC). EBC is an associative motor learning task which involves the paired presentation of a neutral conditioned stimulus (CS), such as a tone, followed by an unconditioned stimulus (US), such as an ocular air puff. The US air puff evokes a reflexive eyeblink, the unconditioned response (UR), and after repeated CS-US paired presentations, a conditioned response (CR), a blink of the eye, forms subsequent to CS presentation. After repeated pairings, the $\mathrm{CR}$ is timed so that the peak eyelid closure occurs near the onset of the US (Gormezano et al, 1983).

All forms of EBC are dependent on cerebellar function, though some forms, such as trace conditioning, also critically depend on the function of the hippocampus (Steinmetz, 2000). The importance of cerebellum in the acquisition of the nictitating membrane/eyeblink response in nonhuman animals has been clearly demonstrated (McCormick et al, 1981; McCormick and Thompson, 1984a, b; Thompson, 1986; Yeo et al, 1985a, b). Although it is difficult to directly assess the neural substrates of EBC in humans, increasing evidence corroborates the nonhuman animal literature (Daum et al, 1993; Topka et al, 1993; Woodruff-Pak et al, 1996). For instance, a PET study showed activation in the inferior cerebellar cortex and deep cerebellar nuclei in humans during eyeblink classical conditioning (Logan and Grafton, 1995). Furthermore, cerebellar morphology and volume in both animals and humans are related to the magnitude of eyeblink conditioning (Woodruff-Pak et al, 2000).

Eyeblink conditioning methodology is well suited for examining cerebellar-based timing deficits in cannabis users. The neural circuitry associated with conditioning is distinct, well characterized, and includes structures and pathways modulated by the cannabinoid system. For example, at several critical nodes in this circuit, particularly granule cell (parallel fiber) to Purkinje cell synapses, excitatory glutamatergic release is modulated (inhibited) by presynaptic CB1 activation (Kreitzer and Regehr, 2001a). More specifically, Purkinje cells activated by glutamatergic granule cells normally serve to inhibit cerebellar deep nuclei (ie interpositus nucleus) thus modulating the timing of conditioned blink responses (CRs) (Steinmetz, 2000). Chronic cannabis use, which is known to produce behavioral tolerance and may induce long-term endocannabinoid compensatory changes (eg CB1 downregulation; Sim et al, 1996; Romero et al, 1998), could result in increased granule cell glutamate release, and hence overactive inhibitory Purkinje inputs to the interpositus. This position is in agreement with a recent study of CB1 knockout animals, in which mice lacking the CB1 receptor exhibit severely disrupted EBC (Kishimoto and Kano, 2006). However, despite the knowledge of dense CB1 presence in the cerebellum, the effect of cannabis use on learningrelated changes in this area in humans is unknown.

To elucidate the long-term effect of cannabinoids on the cerebellum in humans, the current study assessed chronic cannabis users utilizing cerebellar-dependent single-cue delay EBC. Fourteen current cannabis users and 10 healthy drug-free control participants were evaluated. Drug-use status was determined through clinical interviews, drug-use questionnaires, and urine toxicology screens. The primary dependent measures for the eyeblink procedure were percent conditioned responses (\% CRs) and CR peak latency. In addition, fronto-central electroencephalographic (EEG) data were collected to assess attention-dependent event-related potentials (ERPs) to the tone CS. An EEG measure was included to address the possible confound that cannabis-related alterations in sensory/attentional function could affect processing of the tone CS. The N100 component was evaluated, as this ERP is known to be reliably elicited by discreet auditory stimuli (ie tones), and is highly sensitive to attentional allocation (Hillyard et al, 1973; Coull, 1998). As previously observed in CB1 knockout mice (Kishimoto and Kano, 2006), it was hypothesized that cannabis users would show deficits in the acquisition and timing of the CR.

\section{METHODS}

\section{Participants}

Current cannabis users $(n=14)$ and healthy drug-naive controls $(n=10)$ were assessed. This study was approved by the Indiana University Bloomington Human Subjects Committee. Participants were recruited from the local university community, were paid for their participation, and written informed consent was obtained from each. Recruitment consisted of flyers that were posted on the Indiana University campus and in the local Bloomington area which advertised for a paid psychology study for individuals currently using marijuana, but who were free of heavy alcohol use or use of other drugs. The control flyer simply advertised for individuals with no history of illicit drug use and only moderate alcohol use. Potential participants were first screened over the phone to determine if they met our inclusion criteria (see below). After phone screening (of approximately 50 potential subjects), 28 individuals met our inclusion criteria and were invited to participate in the study. Four of these were rejected after the initial clinical interview due to past histories of 
psychopathology. Table 1 illustrates the basic demographic information as well as drug/alcohol use rates. There were no significant differences between the groups in age, years of education, or Wechsler Adult Intelligence Scale (WAIS) scores (Table 1). All participants but two were right handed.

The inclusion criteria were as follows: (1) For the cannabis group: current cannabis consumption (smoked joints) at the rate of at least once per week during the past month, a positive urine toxicology screen for THC, no other illicit substance use during the past 6 months (including a negative urine toxicology screen for other illicit drugs), and no DSM-IV diagnosis of bipolar or schizophrenia spectrum disorders except cannabis abuse or dependence; (2) For the control group: no history of illicit substance use, a negative urine toxicology screen for all drugs tested, and no history of psychiatric illness (Axis I or II); (3) For all participants: ages 18-35, completion of high school education, no family history of bipolar or schizophrenia spectrum disorders, no history of cardiovascular disease, hearing problems, neurological disease, learning disability, or head injury resulting in loss of consciousness. In addition, participants were excluded if they reported consumption of more than two alcoholic drinks per day (one per day for females). The cannabis group drug-use inclusion criteria (cannabis use at least once per week; $24 \mathrm{~h}$ abstinence) were chosen to eliminate acute cannabis effects, while retaining neurophysiological effects from altered CB1 activity. Human studies indicate that $80-90 \%$ of the total amount of THC is excreted within 5 days, so a minimum use of once per week enabled the detection of THC metabolites.

\section{Clinical Interviews, Questionnaires, and Drug-Use Assessment}

The following psychometric questionnaires and clinical interviews were administered to all participants: a substance-use questionnaire, The Drug Abuse Screening Test (DAST; Skinner, 1982), and The Short Michigan Alcoholism Screening Test (SMAST; Selzer et al, 1975). In addition, The Structured Clinical Interview for DSM-IV Axis-I and -II

Table I Demographic and Drug-Use Histories for the Cannabis Group $(n=14)$ and Control Participants $(n=10)$

\begin{tabular}{|c|c|c|c|c|}
\hline Variable & $\begin{array}{c}\text { Cannabis group } \\
\qquad(n=14), \\
\text { mean (SD) }\end{array}$ & $\begin{array}{l}\text { Control group } \\
\qquad(n=10), \\
\text { mean (SD) }\end{array}$ & Value $^{a}$ & $\mathbf{p}^{\mathrm{a}}$ \\
\hline Age (years) & $20.8(2.5)$ & $21.4(2.8)$ & $F=0.32$ & 0.58 \\
\hline Educational level (years) & | $4.3(1.3)$ & |5.| (1.5) & $F=2.04$ & 0.17 \\
\hline WAIS (picture completion) & $12.2(2.4)$ & |3.| (3.5) & $F=0.54$ & 0.47 \\
\hline WAIS (similarities) & । $1.2(2.8)$ & $12.9(2.6)$ & $F=2.23$ & 0.15 \\
\hline WAIS (digit span) & $11.9(3.1)$ & $12.4(1.9)$ & $F=0.18$ & 0.67 \\
\hline Averge cannabis (joints) per week (past month) & $9.7(6.0)$ & $0(0)$ & & \\
\hline Total cannabis use past month & $37.1(18.5)$ & $0(0)$ & & \\
\hline Average alcoholic drinks per week (past month) & $5.6(4.0)$ & I.I ( 1.5$)$ & $F=11.4$ & 0.003 \\
\hline \multirow[t]{2}{*}{ Average number of cigarettes per day (past month) } & $8.4(9.2)$ & $2.0(6.3)$ & $F=3.6$ & 0.07 \\
\hline & n (\%) & $n(\%)$ & & \\
\hline Diagnosis of cannabis abuse & $5(38 \%)$ & $0(0 \%)$ & & \\
\hline Diagnosis of cannabis dependence & $3(21 \%)$ & $0(0 \%)$ & & \\
\hline \multicolumn{5}{|l|}{ Handedness } \\
\hline Right & $12(92 \%)$ & $10(100 \%)$ & & \\
\hline
\end{tabular}

There were no differences between the groups in age, education, or WAIS scores.

${ }^{a}$ One-way ANOVA for the cannabis group vs controls. 
Disorders (SCID I and SCID II; First et al, 1997, 2002) and subscales of the WAIS III (Picture completion, Digit Symbol, Similarities, and Digit Span; Wechsler, 1997) were used to rule out previous psychiatric conditions and general deficits in neuropsychological function.

The clinical interview was used to ascertain current and past diagnoses for alcohol and substance-abuse and dependence. Measures of frequency, quantity, and density of cannabis consumption were determined via the interview for the past 6 months, then for 1 month before the test session. Participants were instructed to consider each day of the week and indicate, for an average week, how much they consumed per drug-use occasion over the past 6 months, and then for the month before testing. Recency and density of last use was assessed using the past month section of the interview. Overall chronicity was assessed using a time-line follow-back procedure (Skosnik et al, 2006a), total months of active use since the onset of initial drug use (of any drug), which accounts for different periods of nonuse, and a measure of overall density of use (total amount ever used/ total months of active use).

Urine screens (Q10-1, Proxam) were administered immediately preceding all testing to corroborate self-reports from the drug questionnaire and clinical interviews. The Q10-1 kit screens for cannabis, opiates, amphetamines, cocaine, MDMA (ecstasy), tricyclic antidepressants, phencyclidine, benzodiazepines, methamphetamines, and barbituates.

\section{EBC Stimuli and Procedure}

Participants engaged in a 148-trial delay EBC paradigm similar to Sears et al (2000) and Brown et al (2005). A visual overview of the experimental set-up can be seen in Figure 1. Initially, eight US alone trials were presented, with an intertrial interval (ITI) of $15 \mathrm{~s}$. Subsequently, the acquisition phase commenced consisting of 10 blocks of trials (mean $\mathrm{ITI}=15 \mathrm{~s}$, range $=10-20 \mathrm{~s}$ ). Each block contained nine CS-US paired trials and one CS-alone trial, which were randomly presented within the last five trials of each block. Paired CS-US trials consisted of a $400 \mathrm{~ms}, 1000 \mathrm{~Hz}$ tone $(80 \mathrm{~dB}$ SPL) with a coterminating $50 \mathrm{~ms}$ air puff. The extinction phase included 25 CS alone and 25 US alone trials, randomly presented across five additional blocks with a mean ITI of $15 \mathrm{~s}$ (range $=10-20 \mathrm{~s}$ ). To maintain attention throughout the procedure, participants were asked to rate the pleasantness of neutral pictures selected from the International Affective Picture System (Lang and Greenwald, 1988). Pictures were presented for $2 \mathrm{~s}$ in between each trial, and participants rated the images on a scale of 1-10 using a button response pad.

Eyeblinks were recorded using pairs of electromyographic (EMG) electrodes (8 mm AG/AGCl; Model TD-23; MedAssociated, St Albans, VT). The electrodes were placed on the orbicularis palpebrarum muscle below each eye, with a ground electrode on the forehead. All electrode impedances were maintained below $5 \mathrm{k} \Omega$. The US consisted of a 10 p.s.i. (50 ms duration) puff of medical-grade air presented to the left eye with copper tubing affixed to eye-glass rims and placed $1 \mathrm{~cm}$ away from the inner canthus of the eye. Foam ear inserts were used for presentation of the CS tones (E-ARLINK - Aearo Company Auditory Systems, Indianapolis, IN). EMG data were continuously recorded at $2.5 \mathrm{kHz}$ with a

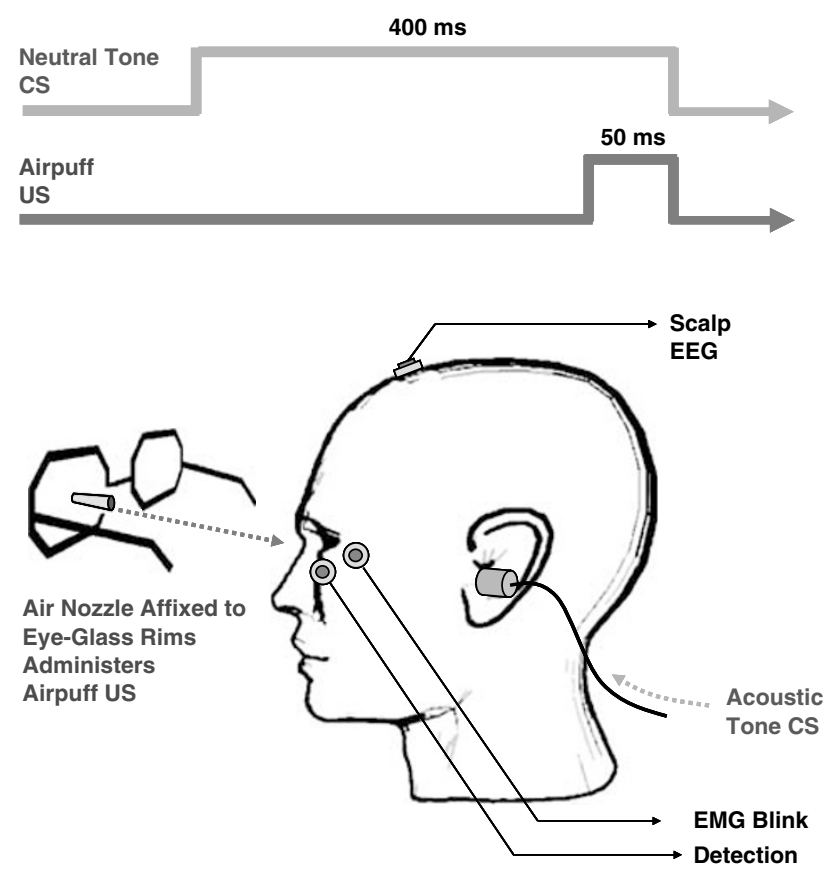

Figure I Experimental setup. Visual overview of the experimental setup showing method and timing of unconditioned stimulus (US) and conditioned stimulus (CS) presentation, and electroencephalographic (EEG)/electromyographic (EMG) recording.

Sensorium EPA-6 bioamplifier (highpass filter $=1 \mathrm{~Hz}$, $12 \mathrm{~dB}$ /octave; lowpass filter $=300 \mathrm{~Hz}$, eighth order elliptic; gain $=5000)$ and acquired using the software Neuroscan (v. 4.2, El Paso, TX).

\section{EBC Data Processing}

Individual trials were epoched $(1086 \mathrm{~ms})$ from the continuous EMG data file beginning $500 \mathrm{~ms}$ before presentation of the CS (using Neuroscan Edit software), and high pass filtered $(10 \mathrm{~Hz}, 6 \mathrm{~dB} /$ octave) before being rectified and smoothed using a 41-point Gaussian weighted moving average. Data were then entered into the software DataMunch for further analysis (King and Tracy, 1999; Tracy et al, 2001). For each subject, responses were recorded as blinks if the amplitude exceeded five standard deviations above the baseline (baseline window for each trial $=125 \mathrm{~ms}$ before CS presentation). CRs were recorded if the blink occurred between 100 and $350 \mathrm{~ms}$ after CS onset (corresponding to a period beginning $250 \mathrm{~ms}$ before US onset). Trials in which spontaneous blinks occur within a window from $75 \mathrm{~ms}$ before CS presentation to $25 \mathrm{~ms}$ following the CS were labeled bad trials and excluded from further analysis.

\section{EEG Recording and Processing}

Electroencephalogram data were concurrently collected during the EBC paradigm. An examination of the N100 ERP component was assessed, which is sensitive to selective attention. This EEG measure was utilized to rule out the possibility that group differences might be due to altered CS encoding resulting from cannabis-related attentional impairments (Skosnik et al, 2001). The EEG was 
recorded continuously (band pass $0.1-100 \mathrm{~Hz}$; sampling rate $1000 \mathrm{~Hz}$ ) from the scalp at electrode site $\mathrm{FCz}$ with a nose reference, along with additional electrodes to record the vertical electrooculogram. The recorded EEG was segmented into epochs consisting of the $400 \mathrm{~ms}$ during stimulus presentation, along with a $50 \mathrm{~ms}$ baseline, with any epoch containing a voltage greater than $\pm 100 \mu \mathrm{V}$ excluded. Ocular movement artifact correction and averages were computed for each frequency block using commercially available software (Neuroscan). For analysis of the transient-evoked response (N100), epochs were low-pass filtered at $20 \mathrm{~Hz}$ (24 dB/octave) before averaging, and baseline corrected (50 ms prestimulus/pre-CS baseline) after averaging. The time window for the N100 component was defined as the largest peak occurring between 90 and $150 \mathrm{~ms}$ after the onset of tone CS. Finally, all experimenters responsible for EBC and EEG data analysis were blind to which experimental group each subject was assigned.

\section{Statistical Analysis}

The primary dependent measures for the eyeblink procedure were \% CRs and CR peak latency. For \% CRs and CR Peak latency during the acquisition phase (10 blocks of paired CS-US trials), a repeated-measures ANOVA was used to assess the between participants effect of group (2) and the within participants effect of block (10). During the five-block extinction phase, a repeated-measures ANOVA was used to assess the between-participants effect of group (2) and block (5). For the 10-block acquisition phase, a similar repeated-measures ANOVA was used to assess the effect of group (2) and block (10) on CR and UR amplitude, and UR onset latency. For the primary dependent variables of \% CRs and CR peak latency, effect sizes are reported (partial $\eta^{2}$ ), where small effect sizes are less than 0.06, moderate effect sizes range from 0.06 to 0.14 , and large effect sizes are greater than 0.14 (Cohen, 1973). Possible group differences in EEG N100 amplitude/latency and questionnaire scores were determined using one-way ANOVAs. All statistical tests used an alpha level of $p<0.05$ to determine significance (two-tailed), and all tests were performed using the software package SPSS 14.0.

\section{RESULTS}

\section{Raw EBC Data}

The primary dependent variables of interest were \% CRs and CR peak latencies during paired trials across the duration of the experiment. Plots of the grand-averaged trial-by-trial EMG data from all the paired CS-US trials can be seen in Figure 2. As can be seen in the outlined sections representing the $\mathrm{CR}$ time window (approximately 220-350 ms), cannabis use was associated with a pronounced deficit in the acquisition of the CR compared to the control participants, particularly from about block 3 to block 10. Both groups showed comparable UR amplitudes (at approximately $400 \mathrm{~ms}$ ), which steadily decreased in amplitude across the acquisition phase due to habituation.

\section{EBC Acquisition Phase}

Percent CRs and CR peak latency during each 10-trial block (plus extinction) were calculated for each group. For \% CRs
(Figure 3), a repeated-measures ANOVA revealed a main effect of block $\left(\mathrm{F}(9,198)=8.67, p<0.0001\right.$; partial $\left.\eta^{2}=0.85\right)$ and a main effect of group $(\mathrm{F}(1,22)=14.36, p<0.001$; partial $\left.\eta^{2}=0.40\right)$. However, there was no group $\times$ block interaction $\left(\mathrm{F}(9,198)=1.89, p=0.14\right.$; partial $\left.\eta^{2}=0.55\right)$. Given that the cannabis group exhibited slightly higher alcohol use rates than controls (see Table 1), the average number of drinks per week (during the past month) was included in the repeated-measures ANOVA as a covariate. The main effect of group remained significant after covarying for alcohol use $(\mathrm{F}(1,21)=9.63, p<0.005$; partial $\left.\eta^{2}=0.31\right)$. Likewise, the group differences also remained significant after covarying for tobacco use per day $\left(\mathrm{F}(1,21)=12.80, p<0.002\right.$; partial $\left.\eta^{2}=0.38\right)$. For CR peak latency, there was also a main effect of block $\left(\mathrm{F}(9,198)=5.17, p<0.003\right.$; partial $\left.\eta^{2}=0.77\right)$ and a main effect of group $\left(\mathrm{F}(1,22)=7.23, p<0.01\right.$; partial $\left.\eta^{2}=0.25\right)$. There was also a trend toward a group $\times$ block interaction $\left(\mathrm{F}(9,198)=2.31, p=0.08\right.$; partial $\left.\eta^{2}=0.60\right)$. The main effect of group remained significant after covarying for tobacco use $\left(\mathrm{F}(1,21)=7.85, p<0.01\right.$; partial $\left.\eta^{2}=0.27\right)$, and fell to a trend level difference after covarying for alcohol use $\left(\mathrm{F}(1,21)=2.79, p<0.10\right.$; partial $\left.\eta^{2}=0.12\right)$. For UR amplitude, no group differences were observed during paired trials $(\mathrm{F}(1,22)=0.71, p=0.41)$ or in UR latency during paired trials $(\mathrm{F}(1,22)=0.02, p=0.9)$. Taken together, the significant group differences in \% CRs and CR peak latency during acquisition demonstrates that the cannabis group showed impaired learning of the conditioned eyeblink response compared to controls (Figure 3), and shorter (less adaptive) peak CR latencies.

\section{EBC Extinction Phase and Auditory Tone CS ERP}

A repeated-measures ANOVA on \% CRs during the last five extinction blocks revealed a main effect of group $\left(\mathrm{F}(1,22)=4.23, p<0.05\right.$; partial $\left.\eta^{2}=0.16\right)$ and a main effect of block $\left(\mathrm{F}(4,88)=3.61, p<0.02\right.$; partial $\left.\eta^{2}=0.43\right)$, which demonstrates that while both groups displayed decreasing $\%$ CRs across extinction, the cannabis group remained significantly below control levels. However, there was no group $\times$ block interaction $(\mathrm{F}(4,88)=0.35, p=0.84$; partial $\left.\eta^{2}=0.07\right)$, demonstrating that extinction rates for the two groups were equal.

For CR peak latency during extinction, there was no effect of group $\left(\mathrm{F}(1,22)=1.8, p=0.21\right.$; partial $\left.\eta^{2}=0.12\right)$, block $\left(\mathrm{F}(4,88)=0.27, \quad p=0.89\right.$; partial $\left.\eta^{2}=0.10\right)$, or group $\times$ block $\left(\mathrm{F}(4,88)=0.74, p=0.59\right.$; partial $\left.\eta^{2}=0.23\right)$, indicating that timing for the remaining CRs was the same in both groups. Likewise for $\mathrm{CR}$ amplitude, there was no effect of group $(\mathrm{F}(1,22)=0.28, p=0.6)$, block $(\mathrm{F}(4,88)=1.3$, $p=0.32)$, or group $\times$ block $(\mathrm{F}(4,88)=1.2, p=0.36)$.

Finally, for the ERP measure, a one-way ANOVA revealed that there were no differences in N100 amplitude between the groups $(\mathrm{F}(1,23)=0.11, p=0.75)$. The grand-averaged EEG waveforms illustrating the N100 ERPs for each group can be seen in Figure 4.

\section{DISCUSSION}

The current study was the first to assess cannabinoid modulation of cerebellar-dependent delay EBC in human 


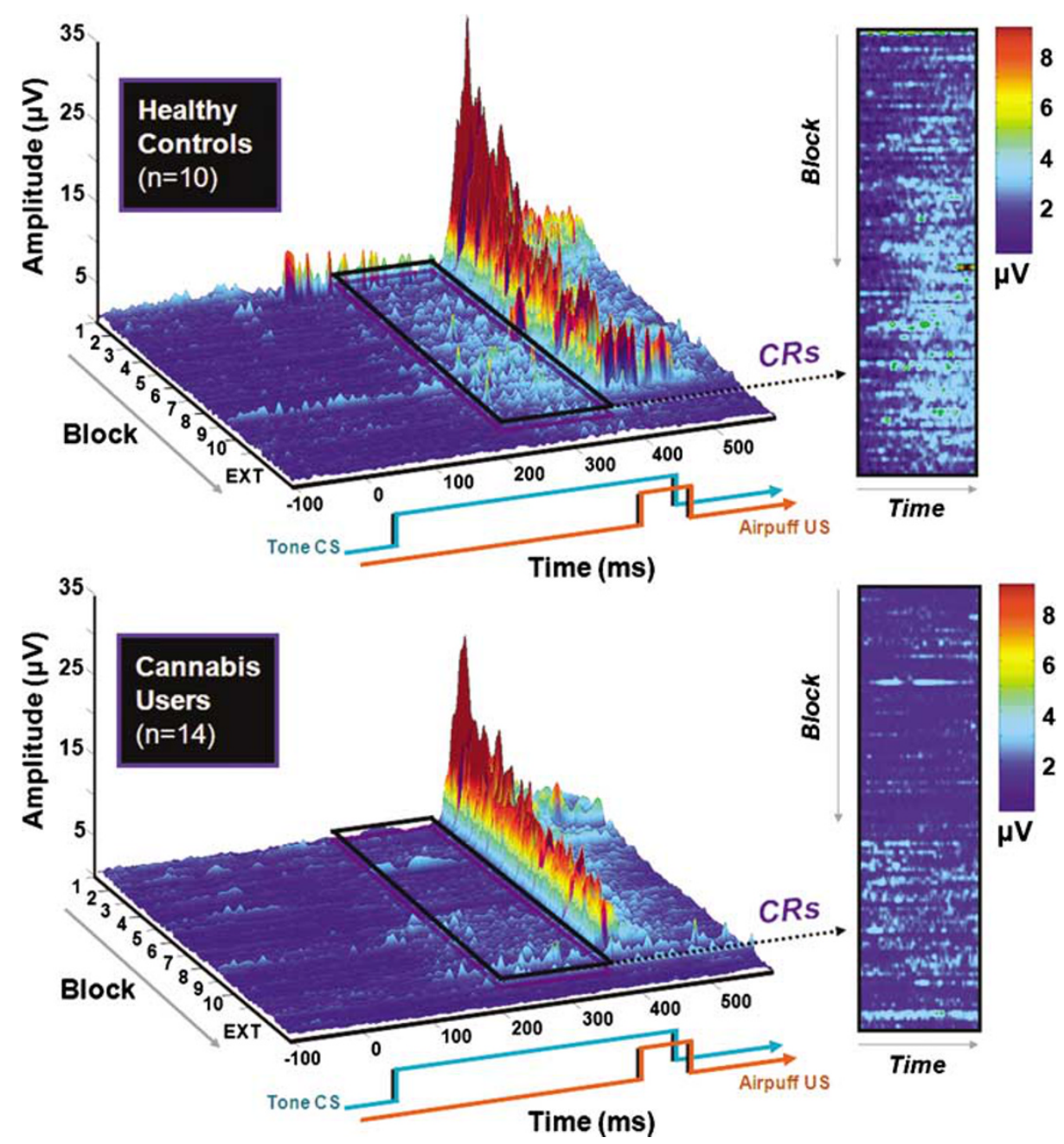

Figure 2 Grand averaged trial-by-trial EMG data from all paired conditioned stimulus-unconditioned stimulus (CS-US) trials. The 400-ms tone CS (I kHz, $80 \mathrm{~dB}$ ) co-terminates with a $50 \mathrm{~ms}$ ( 10 p.s.i.) air puff. The outlined sections and panels display the time window where conditioned responses (CRs) occurred (approximately 220-350 ms). At around block 3, the control participants (top) begin to show robust CRs, as evidenced by the increased amplitude in the period shortly before US onset. Conversely, cannabis users (bottom) are impaired in the acquisition and timing of the CR. Both groups show decreased unconditioned response (UR) amplitudes as the experiment progresses due to habituation.

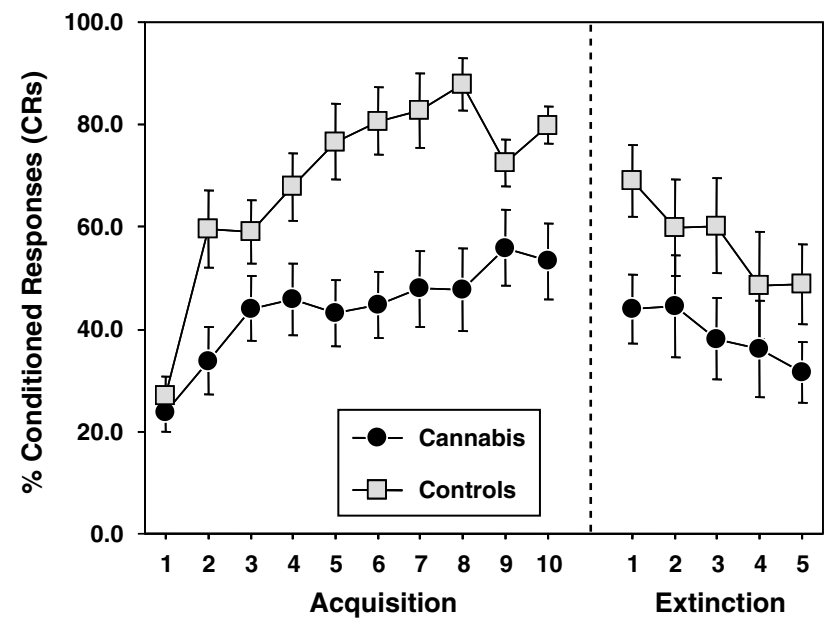

Figure 3 Mean \% conditioned responses (CRs) across blocks (I block= 9 CS-US paired trials) for cannabis users vs controls. Both groups displayed approximately equal \% CRs in the first block of the learning phase, with controls showing greater learning across time. Both groups show similar declines in the percentage of CRs across the extinction blocks, indicating similar rates of extinction of the CR. Error bars indicate \pm SEM. volunteers. These results are in agreement with previous human work showing altered cerebellar activity during cannabis administration (Mathew et al, 1998; O'Leary et al, 2003). In addition to providing further evidence that cannabis use disrupts cerebellar function, the current findings provide an important clue about the specific role endocannabinoids may play in normal cerebellar-dependent learning, particularly in light of the recent study of delay EBC in CB1 knockout animals (Kishimoto and Kano, 2006). Using an animal analogue of the delay EBC learning paradigm, Kishimoto and Kano (2006) have shown that mice lacking the $\mathrm{CB} 1$ receptor display highly impaired acquisition of the $\mathrm{CR}$ compared to wild-type animals. Interestingly, CB1 knockouts showed normal UR amplitudes, CS processing, and unaltered EBC extinction phases, patterns which are also identical to the current human EBC results. It, therefore, appears that the cannabinoid system is primarily involved in the acquisition phase of EBC, with little involvement in CS sensory processing or UR blink generation.

As to the mechanism of $\mathrm{CB} 1$ effects on $\mathrm{EBC}$, both the wellestablished circuitry mediating conditioning (Steinmetz, 2000) and the specified role of endocannabinoids in 


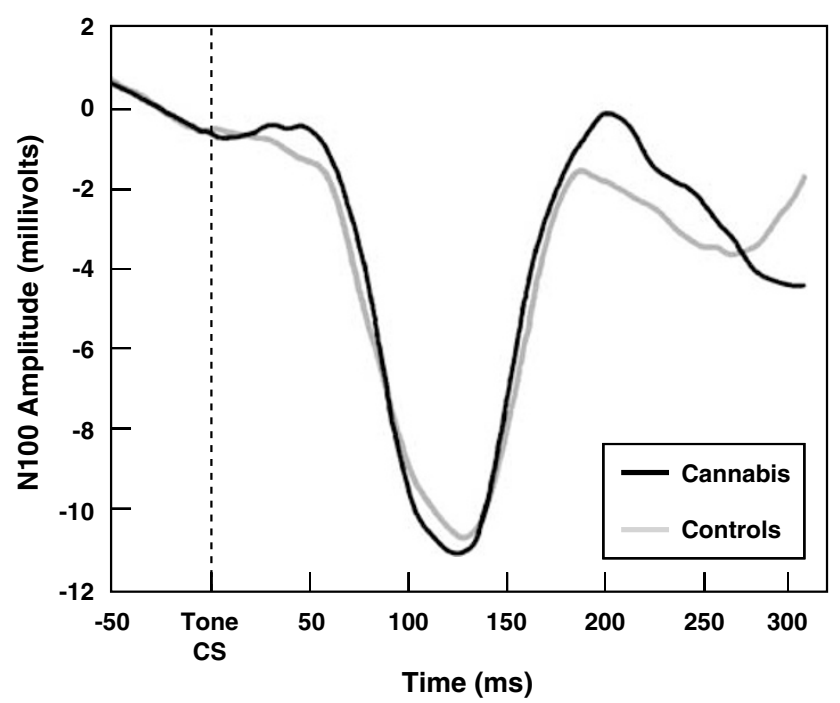

Figure 4 Grand-averaged transient ERPs elicited by tone conditioned stimulus (CS) onset for both cannabis users and control participants at electrode FCz. The similar NIO0 component in the cannabis users and controls provide evidence of intact acoustic stimulus processing and CS encoding in both groups.

cerebellar synaptic function allow for specific hypotheses regarding the role of cannabinoids in EBC. It is thought that information about the CS is projected into the cerebellum via mossy fibers which in turn activate granule cells, while the US is projected into the cerebellum along climbing fibers. Plasticity is thought to occur at neuronal junctions that receive convergent CS-US input (the interpositus nucleus and Purkinje cells in cerebellar cortex). The Purkinje cells that receive convergent CS-US input from granule cells (ie CS) and climbing fibers (ie US) project to the neurons in the interpositus nucleus that also receive convergent CS-US input. The inhibitory Purkinje cells tonically suppress interpositus activity, and it is thought that for conditioning to occur, the GABAergic Purkinje cells must themselves be inhibited, which in turn disinhibits interpositus activity, thus affecting the timing and gain of CRs (Steinmetz, 2000).

In regard to cannabinoid modulation of this circuit, $\mathrm{CB} 1$ receptors are known to reside on glutamatergic granule cell axons (parallel fiber terminals). Purkinje cells synthesize and release retrograde endocannabinoids following bursts of parallel fiber stimulation (Brown et al, 2003). Thus, during EBC, endocannabinoids may operate by activating presynaptic $\mathrm{CB} 1$ receptors on parallel fiber terminals, which reduce $\mathrm{Ca}^{2+}$ influx, ultimately inhibiting Purkinje cell activity by decreasing glutamate release from parallel fiber terminals. Indeed, it has recently been shown that concurrent parallel fiber/climbing fiber activation of Purkinje cells (which is analogous to convergent CS-US input) leads to short-term depression of the parallel fiber synapse, an effect which is mediated by endocannabinoids (Brenowitz and Regehr, 2005). Such an effect may be crucial for the induction of longer-lasting synaptic plasticity, such as endocannabinoid-mediated long-term depression (LTD; Safo and Regehr, 2005), which itself may represent the neural substrate of EBC (Thompson and Kim, 1996).

In the context of chronic cannabis use, long-term activation of presynaptic parallel fiber CB1 by exogenous THC may act to desensitize or downregulate the receptors, which could disrupt the short-term plasticity and/or LTD necessary for learning in the cerebellum. It has already been established that chronic cannabis users assessed during periods of abstinence demonstrate hypoactive cerebellar activity, which could be interpreted as neuroadaptive endocannabinoid downregulation (Volkow et al, 1996; Block et al, 2000; Chang et al, 2006). Indeed, animal studies have shown that behavioral tolerance to the motor effects of THC is likely mediated by CB1 downregulation throughout the cerebellum (Sim et al, 1996; Romero et al, 1998). More recently, it has been found that chronic cannabis use in humans does in fact lead to significant $\mathrm{CB} 1$ downregulation as determined via postmortem $\left[{ }^{3} \mathrm{H}\right] \mathrm{SR} 141716 \mathrm{~A}$ binding (Villares, 2007). These data provide indirect evidence that cerebellar changes in $\mathrm{CB} 1$ induced by chronic cannabis intake may partly explain the impaired EBC performance observed in the current study.

Several limitations of the current study warrant further discussion. First, since participants were tested after $24 \mathrm{~h}$ of abstinence, it is unclear whether THC withdrawal may have accounted for the observed findings. However, most heavy cannabis users do not display peak withdrawal symptoms until 2-3 days following the cessation of use (Budney et al, 2004), which most likely precludes the possibility that the current results were due to cannabis withdrawal. However, a related confound is that participants in the current experiment were not monitored during the $24 \mathrm{~h}$ abstinence window. Thus, the veracity of participants' self-reported cannabis use $24 \mathrm{~h}$ pre-experiment could be unreliable, meaning that acute intoxication or residual THC may have contributed to EBC learning deficits.

A second limitation of the current study is that even though both groups displayed moderate-to-low levels of alcohol and tobacco use, the cannabis group had slightly increased rates of consumption of these substances. However, current weekly levels of alcohol and tobacco use were included as covariates in each of the analyses of $\mathrm{EBC}$ performance (\% CRs and CR peak latency), which in turn, did not influence the observed effects. In relation to tobacco use, nicotine administration has actually been shown to increase EBC performance in animals (Woodruff-Pak et al, 1994, 2000). This, along with the fact that the onset of nicotine withdrawal is $2 \mathrm{~h}$ and peaks around $36 \mathrm{~h}$ (tobacco use was permitted in our subjects up to $1 \mathrm{~h}$ before testing; Hughes et al, 1994; Kenny and Markou, 2001), most likely rules out that possibility that tobacco use or withdrawal contributed to the current findings.

Thirdly, since the current study did not directly administer cannabis or THC, it remains possible that some preexisting condition contributed to both cannabis drugseeking and altered EBC performance (eg premorbid alterations in CB1 or endocannabinoids). However, since all of the current cannabis subjects tested positive for THC, and had a mean of 5.6 years of cannabis use, the informed assumption of $\mathrm{CB} 1$ downregulation discussed above is likely more proximal and salient than subtle preexisting individual differences in endocannabinoid activity. Nonetheless, since there was no way of directly assessing CB1 densities in the current sample, possible preexisting differences cannot be ruled out using the current methodology.

Several additional limitations of the current experiment exist which could be addressed by future studies including the small sample size, the generalizability of the findings 
given the homogeneity of the groups, and whether the observed deficits would normalize following longer periods of abstinence. This last issue regarding whether EBC performance is recoverable will be important to elucidate from a public health perspective. Current neuropsychological data suggest a recovery of cannabis-induced cognitive impairments after 1 month of abstinence (Pope et al, 2001; Harrison et al, 2002). However, these neuropsychological tasks are typically sensitive to distributed cortical networks not specific to cerebellar processes, as is the EBC procedure. It therefore remains feasible that compensatory mechanisms of diverse brain regions (ie neocortical) may partially explain the recovery of function on classical neuropsychological tasks. Future studies are planned which will attempt to address these issues, including assessing past cannabis users on EBC, and the use of alternate cerebellar tasks (eg paced finger tapping and postural sway) which could corroborate the finding of altered cerebellar-dependent learning using EBC. Prospective experiments on chronic cannabis users would also benefit from identified behavioral patterns of CB1 knockout animals. Given that CB1 knockout mice exhibit alterations on tests assessing extinction of fear conditioning, pain thresholds, locomotor activity, and spatial memory, developing human analogues of these tasks for application in cannabis users would seem prudent.

In summary, the overall implications and relevance of the current study are twofold: first, the observed effects provide evidence that endocannabinoids may be critically involved in cerebellar EBC. Second, the fact that chronic cannabis users exhibit learning patterns similar to $C B 1$ knockout animals suggests that long-term use may produce physiological alterations (ie CB1 downregulation) of a magnitude previously unreported. Given that the cerebellum is reciprocally connected to vast regions of brain (Dum and Strick, 2003) and is now implicated in a host of nonmotor functions including perception and cognition (Katz and Steinmetz, 2002), it is imperative that future human and animal studies further assess the role of cannabinoids in cerebellar function.

\section{ACKNOWLEDGEMENTS}

This work was supported in part by a grant from NIDA (NIDA 1 R03 DA019630-01) and a NARSAD Young Investigator Award. We thank Michael Walker, Jo Anne Tracy, Jennifer Vollmer, Ken Mackie, and Michael Paulin for their help throughout the project.

\section{CONFLICT OF INTEREST}

The authors declare that they have no competing financial interests.

\section{REFERENCES}

Bengtsson SL, Ehrsson HH, Forssberg H, Ullen F (2005). Effectorindependent voluntary timing: behavioural and neuroimaging evidence. Eur J Neurosci 22: 3255-3265.

Block RI, O'Leary DS, Hichwa RD, Augustinack JC, Ponto LL, Ghoneim MM et al (2000). Cerebellar hypoactivity in frequent marijuana users. Neuroreport 11: 749-753.
Brenowitz SD, Regehr WG (2005). Associative short-term synaptic plasticity mediated by endocannabinoids. Neuron 45: 419-431.

Brown SM, Kieffaber PD, Carroll CA, Vohs JL, Tracy JA, Shekhar A et al (2005). Eye-blink conditioning deficits indicate timing and cerebellar abnormalities in schizophrenia. Brain Cogn 58: 94-108.

Brown SP, Brenowitz SD, Regehr WG (2003). Brief presynaptic bursts evoke synapse-specific retrograde inhibition mediated by endogenous cannabinoids. Nat Neurosci 6: 1048-1057.

Budney AJ, Hughes JR, Moore BA, Vandrey RG (2004). A review of the validity and significance of the cannabis withdrawal syndrome. Am J Psychiatr 161: 1967-1977.

Chang L, Yakupov R, Cloak C, Ernst T (2006). Marijuana use is associated with a reorganized visual-attention network and cerebellar hypoactivation. Brain 129(Part 5): 1096-1112.

Cohen J (1973). Eta-squared and partial eta-squared in communication science. Hum Commun Res 28: 473-490.

Coull JT (1998). Neural correlates of attention and arousal: insights from electrophysiology, functional neuroimaging and psychopharmacology. Prog Neurobiol 55: 343-361.

Daum I, Schugens M, Ackermann H, Lutzenberger W, Dichgans J, Birbaumer N (1993). Classical conditioning after cerebellar lesions in humans. Behav Neurosci 107: 748-756.

Devane WA, Dysarz III FA, Johnson MR, Melvin LS, Howlett AC (1988). Determination and characterization of a cannabinoid receptor in rat brain. Mol Pharmacol 34: 605-613.

Devane WA, Hanus L, Breuer A, Pertwee RG, Stevenson LA, Griffin $\mathrm{G}$ et al (1992). Isolation and structure of a brain constituent that binds to the cannabinoid receptor. Science 258: 1946-1949.

Dum RP, Strick PL (2003). An unfolded map of the cerebellar dentate nucleus and its projections to the cerebral cortex. J Neurophysiol 89: 634-639.

First MB, Spitzer RL, Gibbon M, Williams JBW (1997). Structured Clinical Interview for DSM-IV Personality Disorders (SCID-II). American Psychiatric Press, Inc.: Washington, DC.

First MB, Spitzer RL, Gibbon M, Williams JBW (2002). Structured Clinical Interview for DSM-IV-TR Axis I Disorders, Research Version, Patient Edition. (SCID-I/P). Biometrics Research, New York State Psychiatric Institute: New York.

Gaoni Y, Mechoulam R (1964). Isolation, structure, and partial synthesis of an active constituent of hashish. J Am Chem Soc 86: 1646-1647.

Gormezano I, Kehoe EJ, Marshall BS (1983). Twenty years of classical conditioning with the rabbit. Prog Psychobiol Physiol Psychol 10: 197-275.

Harrison Jr GP, Gruber AJ, Hudson JI, Huestis MA, YurgelunTodd D (2002). Cognitive measures in long-term cannabis users. J Clin Pharmacol 42(11 Suppl): 41S-47S.

Herkenham M, Lynn AB, Little MD, Johnson MR, Melvin LS, de Costa BR et al (1990). Cannabinoid receptor localization in brain. Proc Natl Acad Sci USA 87: 1932-1936.

Hicks RE, Gualtieri CT, Mayo Jr JP, Perez-Reyes M (1984). Cannabis, atropine, and temporal information processing. Neuropsychobiol 12: 229-237.

Hillyard SA, Hink RF, Schwent VL, Picton TW (1973). Electrical signs of selective attention in the human brain. Science 182: 177-180.

Hughes JR, Higgins ST, Bickel WK (1994). Nicotine withdrawal versus other drug withdrawal syndromes: similarities and dissimilarities. Addiction 89: 1461-1470.

Iversen L (2003). Cannabis and the brain. Brain 126(Part 6): $1252-1270$.

Ivry RB, Keele SW (1989). Timing of functions of the cerebellum. J Cogn Neurosci 1: 136-152.

Jager G, Van Hell HH, De Win MM, Kahn RS, Van Den Brink W, Van Ree JM et al (2007). Effects of frequent cannabis use on hippocampal activity during an associative memory task. Eur Neuropsychopharmacol 17: 289-297.

Katz DB, Steinmetz JE (2002). Psychological functions of the cerebellum. Behav Cogn Neurosci Rev 1: 229-241. 
Kenny PJ, Markou A (2001). Neurobiology of the nicotine withdrawal syndrome. Pharmacol Biochem Behav 70: 531-549.

King DAT, Tracy J (1999). Datamunch: a Matlab m-file collection for the analysis of trial-based spike and behavioral data. Available from: http://www.novl.indiana.edu/ dmunch/.

Kishimoto Y, Kano M (2006). Endogenous cannabinoid signaling through the CB1 receptor is essential for cerebellar-dependent discrete motor learning. J Neurosci 26: 8829-8837.

Kreitzer AC, Regehr WG (2001a). Retrograde inhibition of presynaptic calcium influx by endogenous cannabinoids at excitatory synapses onto Purkinje cells. Neuron 29: 717-727.

Lang PJ, Greenwald MK (1988). The International Affective Picture System Standardization Procedure and Initial Group Results for Affective Judgments: Technical Report 1A. The Center for Research in Psychophysiology, University of Florida: Gainesville, FL.

Leiner HC, Leiner AL, Dow RS (1991). The human cerebrocerebellar system: its computing, cognitive, and language skills. Behav Brain Res 44: 113-128.

Logan CG, Grafton ST (1995). Functional anatomy of human eyeblink conditioning determined with regional cerebral glucose metabolism and positron-emission tomography. Proc Natl Acad Sci USA 92: 7500-7504.

Mathew RJ, Wilson WH, Turkington TG, Coleman RE (1998). Cerebellar activity and disturbed time sense after THC. Brain Res 797: 183-189.

McCormick DA, Lavond DG, Clark GA, Kettner RE, Rising CE, Thompson RF (1981). The engram found? Role of the cerebellum in classical conditioning of nictitating membrane and eyelid responses. Bull Psychon Soc 18: 103-105.

McCormick DA, Thompson RF (1984a). Cerebellum essential involvement in the classically conditioned eyelid response. Science 223: 296-299.

McCormick DA, Thompson RF (1984b). Neuronal responses of the rabbit cerebellum during acquisition and performance of a classically conditioned nictitating membrane-eyelid response. J Neurosci 4: 2811-2822.

O’Leary DS, Block RI, Turner BM, Koeppel J, Magnotta VA, Ponto LB et al (2003). Marijuana alters the human cerebellar clock. Neuroreport 14: 1145-1151.

Patrick G, Straumanis JJ, Struve FA, Nixon F, Fitz-Gerald MJ, Manno JE et al (1995). Auditory and visual P300 event related potentials are not altered in medically and psychiatrically normal chronic marihuana users. Life Sci 56: 2135-2140.

Patrick G, Straumanis JJ, Struve FA, Fitz-Gerald MJ, Manno JE (1997). Early and middle latency evoked potentials in medically and psychiatrically normal daily marihuana users: a paucity of significant findings. Clin Electroencephalogr 28: 26-31.

Pertwee RG (1997). Pharmacology of cannabinoid CB1 and CB2 receptors. Pharmacol Ther 74: 129-180.

Pope HG, Gruber AJ, Hudson JI, Huestis MA, Yurgelun-Todd D (2001). Neuropsychological performance in long-term cannabis users. Arch Gen Psychiatry 58: 909-915.

Ramaekers JG, Kauert G, van Ruitenbeek P, Theunissen EL, Schneider E, Moeller MR (2006). High-potency marijuana impairs executive function and inhibitory motor control. Neuropsychopharmacology 31: 2296-2303.

Romero J, Berrendero F, Garcia-Gil L, Ramos JA, Fernandez-Ruiz JJ (1998). Cannabinoid receptor and WIN-55,212-2-stimulated [35S]GTP gamma S binding and cannabinoid receptor mRNA levels in the basal ganglia and the cerebellum of adult male rats chronically exposed to delta 9-tetrahydrocannabinol. J Mol Neurosci 11: 109-119.

Safo PK, Regehr WG (2005). Endocannabinoids control the induction of cerebellar LTD. Neuron 48: 647-659.

Sears LL, Andreasen NC, O'Leary DS (2000). Cerebellar functional abnormalities in schizophrenia are suggested by classical eyeblink conditioning. Biol Psychiatry 48: 204-209.

Selzer ML, Vinokur A, van Rooijen L (1975). A self-administered Short Michigan Alcoholism Screening Test (SMAST). J Stud Alcohol 36: 117-126.
Sim LJ, Hampson RE, Deadwyler SA, Childers SR (1996). Effects of chronic treatment with delta9-tetrahydrocannabinol on cannabinoid-stimulated [35S]GTPgammaS autoradiography in rat brain. J Neurosci 16: 8057-8066.

Skinner HA (1982). The drug abuse screening test. Addict Behav 7: 363-371.

Skosnik PD, Krishnan G, Aydt AE, Kuhlenschmidt H, O’Donnell BF (2006a). Psychophysiological evidence of altered neural synchronization in cannabis use: relationship to schizotypy. Am J Psychiatr 163: 1798-1805.

Skosnik PD, Krishnan G, Vohs J, O’Donnell BF (2006b). The effect of cannabis use and gender on the visual steady state evoked potential. Clin Neurophysiol 117: 144-156.

Skosnik PD, Spatz-Glenn L, Park S (2001). Cannabis use is associated with schizotypy and attentional disinhibition. Schizophr Res 48: 83-92.

Steinmetz JE (2000). Brain substrates of classical eyeblink conditioning: a highly localized but also distributed system. Behav Brain Res 110: 13-24.

Stella N, Schweitzer P, Piomelli D (1997). A second endogenous cannabinoid that modulates long-term potentiation. Nature 388: 773-778.

Substance Abuse Mental Health Services Administration (2004). Results from the 2003 National Survey on Drug Use and Health: National Findings NSDUH Series H-25. DHHS Pub. No. (SMA) 04-3964 SAMHSA: Rockville, MD.

Thompson RF (1986). The neurobiology of learning and memory. Science 223: 941-947.

Thompson RF, Kim JJ (1996). Memory systems in the brain and localization of a memory. Proc Natl Acad Sci USA 93: 13438-13444.

Topka H, Valls-Sole J, Massaquoi SG, Hallett M (1993). Deficit in classical conditioning in patients with cerebellar degeneration. Brain 116: 961-969.

Tracy JA, Britton GB, Steinmetz JE (2001). Comparison of single unit responses to tone, light, and compound conditioned stimuli during rabbit classical eyeblink conditioning. Neurobiol Learn Mem 76: 253-267.

Tsou K, Brown S, Sanudo-Pena MC, Mackie K, Walker JM (1998). Immunohistochemical distribution of cannabinoid CB1 receptors in the rat central nervous system. Neurosci 83: 393-411.

Villares J (2007). Chronic use of marijuana decreases cannabinoid receptor binding and mRNA expression in the human brain. Neuroscience 145: 323-334.

Volkow ND, Gillespie H, Mullani N, Tancredi L, Grant C, Valentine A et al (1996). Brain glucose metabolism in chronic marijuana users at baseline and during marijuana intoxication. Psychiatr Res 67: 29-38.

Wechsler D (1997). Wechsler Adult Intelligence Scale. Ed 3. The Psychological Corporation: San Antonio, TX.

Woodruff-Pak DS, Goldenberg G, Downey-Lamb MM, Boyko OB, Lemieux SK (2000). Cerebellar volume in humans related to magnitude of classical conditioning. Neuroreport 11: 609-615.

Woodruff-Pak DS, Green JT, Coleman-Valencia C, Pak JT (2000). A nicotinic cholinergic agonist (GTS-21) and eyeblink classical conditioning: acquisition, retention, and relearning in older rabbits. Exp Aging Res 26: 323-336.

Woodruff-Pak DS, Li YT, Kem WR (1994). A nicotinic agonist (GTS-21), eyeblink classical conditioning, and nicotinic receptor binding in rabbit brain. Brain Res 645: 309-317.

Woodruff-Pak DS, Papka M, Ivry RB (1996). Cerebellar involvement in eyeblink classical conditioning in humans. Neuropsychol 10: $443-458$.

Yeo CH, Hardiman MJ, Glickstein M (1985a). Classical conditioning of the nictitating membrane response of the rabbit I. Lesions of the cerebellar nuclei. Exp Brain Res 60: 87-98.

Yeo CH, Hardiman MJ, Glickstein M (1985b). Classical conditioning of the nictitating membrane response of the rabbit II. Lesions of the cerebellar cortex. Exp Brain Res 60: 99-113. 